Filmmaking, Logic and the Historical Reconstruction of the World

\author{
Evan Wm. Cameron \\ Professor Emeritus \\ Senior Scholar in Screenwriting \\ Graduate Programmes, \\ Film \& Video and Philosophy \\ York University
}

[Written in April 1995 at the request of the editors of a new journal, Film \& Philosophy, the essay appeared within its second volume in the fall of the year (Film \& Philosophy, Volume II (1995), pages 88-104). The presentation of the argument of Karl Popper on page 9 has been reformatted to render it more easily understood.] 


\section{Filmmaking, Logic and the Historical Reconstruction of the World}

... Identity is the very Devil and immensely important; very much more so than I thought. It hangs - like everything else - directly together with the most fundamental questions, especially with the questions concerning the occurrence of the same argument in different places of a function. I have all sorts of ideas for a solution of the problem but could not yet arrive at anything definite. However, I don't lose courage and go on thinking.

\section{Ludwig Wittgenstein (1913) $)^{1}$}

[Speaking of negation]. The question here is: Is the positive fact primary, and the negative secondary, or are they on the same level? And if so, how is it with the facts $p \vee q, p$ only if $q$, etc.? Aren't these on the same level as $-p$ ? But then must not all facts be on the same level? The question is really this: Are there facts besides the positive ones? (For it is difficult not to confuse what is not the case with what is the case instead of it.) ...

It is the dualism, positive and negative facts, that gives me no peace. For such a dualism can't exist. But how are we to get away from it?

$$
\text { Ludwig Wittgenstein (1914) }{ }^{2}
$$

No other medium of expression has the cinema's original and innate capacity for showing things, that we believe worth showing, as they happen day by day ... .

Cesare Zavattini ${ }^{3}$

\footnotetext{
${ }^{1}$ From a letter to Bertrand Russell, written in Norway on 29 October 1913, reproduced
} in part in Appendix III of Notebooks 1914-1916, edited by G. H. von Wright and G. E. M. Anscombe (Cambridge, England: Cambridge University Press, 1969), page 122.

${ }^{2}$ From a set of remarks entered into a notebook on 25 November 1914, translated into English by G. E. M. Anscombe and reproduced on pages 33/33e of Notebooks 1914-1916 [see footnote 1].

${ }^{3}$ Cesare Zavattini, Sequences from a Cinematic Life, translated and introduced by William Weaver (Englewood Cliffs, New Jersey: Prentice-Hall, Incorporated, 1970 [original Italian edition, 1967]), page 220. 
Twenty-five hundred years ago, as the arts of our civilisation dawned in Attica, Parmenides warned his followers to avoid negation, for they would otherwise find the identity of the world incomprehensible and be tempted to deny it. ${ }^{4}$ Parmenides' caution went unheeded. The logic by which philosophers from Aristotle through Frege to Quine have tried to render the world coherent has rested resolutely, despite occasional dissenters, upon a notion of negation presumed to be intelligible. The presumption, as Parmenides forewarned, has rendered unintelligible the identity of the world.

In 1971 Stanley Cavell protested against the common disavowal of the 'mysterious' identities entailed by photographs and films, echoing in the deafening silence the sentiments of André Bazin, Erwin Panofsky and, unwittingly, Siegfried Kracauer. ${ }^{5}$ In 1975 Sol Worth, upset by the semiotic sludge obstructing anthropologists trying to make films, suggested specifically that filmmaking must be an endeavour unlike language as commonly construed, for the expression of negation is cinematically impossible. ${ }^{6}$ And by 1985 it had become obvious, at least to Nelson Goodman, the most cautious yet audacious of philosophers, that the uniqueness and hence identity of the world had been rendered unintelligible: there must be, negation presumed, as many worlds as right world-descriptions. ${ }^{7}$

Cavell and Worth were ignored, trivialized or swept aside by the political tides of semiotics. Goodman, having friends in high places, was, as usual, bypassed in reverent disbelief. Goodman, however, in company with the giants of philosophy from Plato

${ }^{4}$ See S. Wheeler, "Megarian Paradoxes as Eleatic Arguments", American Philosophical Quarterly 20 (1983), pp. 287-95. I am indebted to Laurence R. Horn's A Natural History of Negation (Chicago: University of Chicago Press, 1989), page 50, for this reference and for the quotation from Russell in footnote 20 . Horn's remarkable book has been a constant companion and provocation during the writing of this essay.

${ }^{5}$ Stanley Cavell, The World Viewed: Reflections on the Ontology of Film (New York: Viking Press, 1971), especially chapter 2, 'Sights and Sounds.' "It may be felt that I make too great a mystery of these objects [films and photographs]. My feeling is rather that we have forgotten how mysterious these things are, and in general how different things are from one another, as though we had forgotten how to value them. This is in fact something movies teach us." This little book has influenced me beyond measure for a quarter-century, augmented by Cavell's later reflections on related matters.

${ }^{6}$ Sol Worth, "Pictures Can't Say Aint", Versus 12 (1975), pages 85-108. Reprinted in Tony Thomas and Rudy Behlmer, Hollywood's Hollywood (New York: Citadel Press, 1975).

${ }^{7}$ Nelson Goodman, Ways of Worldmaking (Indianapolis: Hackett Publishing Company, 1978), especially chapters 1,6 and 7. I shall hereafter refer to this book as Goodman, WWM. Goodman is here clarifying and expanding conclusions expressed in 1960 in "The Way the World Is", Review of Metaphysics 14 (1960), pages 48-56, upon which Richard Rorty later capitalized in "The World Well Lost", Journal of Philosophy 69 (1972), pages 649-65. 
through Kant to Wittgenstein, who began by pondering the perplexities of the exact sciences only to end in art, went beyond them to suggest and rightly, as we shall see, that the making of works of art, those events that most freely exemplify worlds, must be the model for worldmaking in general. ${ }^{8}$ We learn at our best to make worlds artistically, and hence, although Goodman never says so, learning to identify works of art must be the model for learning to identify in general.

I wish in this essay to return to Parmenides by making a world, in Goodman's sense, so absurd and wondrous that readers may at first glance fail to recognize it as a world remade, again in Goodman's sense - a reconstruction of the logical world whose incoherence we have been trained to disregard. In a style learned from Quine, Goodman and Davidson, but austerely redirected, I shall sketch a world in which all things may be identified and yet distinguished, in which falsity and negation are unintelligible, in which truth is ubiquitous and non-discriminatory and in which the crafty arts like filmmaking are the models for scientific, philosophical and logical construction. I shall introduce the world historically, and, after Collingwood and Kuhn, accept its historicity as part of the logical lesson to be learned. And I shall conclude, with Parmenides, that it is the only world available to us.

To those unaccustomed to traversing the wintry wilderness in which my kind of pragmatism flourishes, I may appear to be skiing across a pond vast and deep, oblivious to the creaking of stressed ice beneath the snow. If so, I should remind you that one may travel more securely within my pristine logical landscape than in more populated vistas to the south, if only one knows and respects the ice, checks one's equipment before departing and travels light. Should you choose to follow, and fall through the ice, chances are good the logical baggage you are carrying is excessive.

8 "Rather than attempting to subsume descriptive and representational rightness under truth, we shall do better, I think, to subsume truth along with these under the general notion of rightness of fit." (Goodman, WWM, page 132) Goodman is here amplifying "Art and the Understanding", the concluding section of his Languages of Art (Indianapolis: Hackett Publishing Company, 1976), pages 262-65. 


\section{Lumière's Identities ${ }^{9}$}

In 1895 Louis Lumière stood on a quay in the railway station at La Ciotat in southern France awaiting the arrival of a train. Beside him stood a curious machine that he had constructed, one of the first motion picture cameras. As the train pulled into the station, Lumière aimed his camera and turned the crank. The train rolled to a stop and the passengers disembarked, walking past the camera on their way into the depot. Finally, having exhausted his reel of film, Lumière stopped cranking the camera.

Several months later, on 28 December 1895, thirty-five persons gathered in the Salon Indien in the basement of the Grand Café on the Boulevard des Capucines in Paris having purchased tickets to the first paid public screenings in a 'cinema'. During the evening a roll of film printed from the strip exposed at the train station was placed inside the machine now converted into a projector. The lights were dimmed, the projector's lamp was lit, the spectators gazed at a screen hung at the end of the room and the projectionist began to crank the projector.

What did Louis Lumière see as he peered in the ensuing moments at the screen in the darkened room? More precisely, what kinds of events did he encounter visually as he focused his eyes upon the illuminated screen hanging before him ${ }^{10}$

Unlike some in the audience, Lumière knew exactly what he was seeing. He knew, on the one hand, that he was focusing upon a screen whose surface was being variably illuminated by the intermittent light impinging upon it from the projector. He was therefore encountering an object in the room before him, the surface of the screen, under conditions of cinematic illumination. On the other hand, he knew that he was also encountering, and by the same act of seeing, an event distinguishable from the former, for he was seeing, as well, a train pulling into a station and passengers disembarking onto a quay and exiting - the same train, station, passengers, quay and event that he had encountered some months before while filming them.

${ }^{9} \mathrm{~A}$ preliminary assessment of the situations described in this section and the next appeared in my essay "Kant's Station; the Lumières' Train: Seeing Things by Means of Film", Canadian Journal of Film Studies 1, No. 1 (1990), pages 36-56. A comparison of the film-theoretic context of that discussion to the more radical assessment given here may be of interest.

${ }^{10}$ Throughout this essay I shall use the word 'encounter' as equivalent to Kant's 'Anschauung', a noun usually translated into English, with appropriate misgivings, as 'intuition'. The comprehension of Kant by students, and by many scholars as well, would be significantly advanced were the word 'intuition' to be banned from all translations, and the word 'encounter' put in its place. 
Lumière, thankfully, was untrained as a logician and prepared to act without question or quibble upon the remarkable identifications and distinctions he was unwittingly making. It was obvious to him that:

(a) he was encountering the surface of the screen in the room before him under conditions of cinematic illumination, the only event occurring in the room to be encountered; and yet

(b) he was encountering, by the same act of seeing, an event occurring elsewhere than in the room before him, an event distinguishable therefore from the former;

(c) he could identify event (b) with an event that he had encountered in another place some months earlier; hence

(d) he could both distinguish and identify events (a), (b) and (c).

Put another way, Lumière presupposed that he could both distinguish and identify the events he encountered to whatever degree might prove useful. But that suggests that ascriptions of identity are relative.

I shall presume without argument, however absurd it may seem, that Lumière (and thereafter every working filmmaker, protestations to the contrary notwithstanding) was correct in the identifications and distinctions that he made. Simply by being born and raised within a world of trains, passengers, quays and cameras, Lumière had trained himself to discriminate and identify rightly what he was seeing by means of films. To claim otherwise is to misunderstand filmmaking and therewith the mysteries of identity that philosophy and its logic must accommodate.

Consequently, I shall argue that there must be less to logic than we are accustomed to pretending. Logic, like filmmaking and every other art, is a constructive rather than critical endeavour, and we who would think precisely must learn to avoid begging the questions that have made it seem more than it is. To understand how this must be, however, we must, as Robin Collingwood insisted, comprehend it historically. I begin my historical reconstruction, however, with a blunt commentary on identity itself. 


\section{Identity and Negative Inference}

On the desk before me lies a pen. It weighs 5 grams, is black with silver trim and might break if dropped. On my desk, as well, sits a book. The book weighs 500 grams, has a red cover and could well survive a casual fall.

I wish now to ask a question so peculiar that I know of no comparable query in the entire history of philosophy, namely, is the pen identical to the book? ${ }^{11} \mathrm{l}$, of course, believe the pen and the book to be distinct and have no reason whatever to believe them identical. But what if someone were to claim they were identical? What counterevidence could we bring against the claim?

Suppose someone were to enter my room and, in the course of conversation, express admiration for the book, suggesting that she had long sought a hardcover edition like my own. I, having another copy, offer to sell it to her. She writes me a check, thanks me profusely, picks up the book and my pen and prepares to exit the room. When I, dumbfounded, ask what she is doing with my pen, she, equally dumbfounded, replies that she just bought it. ${ }^{12}$ What evidence could I now bring against her claim? If I were to say to her, for example, "But the pen weighs 5 grams while the book weighs 500 grams", she would reply, "True enough, it weighs both 5 grams and 500 grams." Were I to retort, "But surely an object cannot weigh both 5 grams and 500 grams!", she would simply point to the pen/book (whichever, or both, from my viewpoint) and say, "But there's a counterexample!"

Note my dilemma! Whenever I attempt to point out a difference between the pen and the book, she accepts the distinction but construes it adverbially rather than adjectivally, retaining the identity to which she is accustomed. Every time I propose an empirical test, she agrees to the test (for example, the pen/book weighs 5 grams and

${ }^{11} \mathrm{By}$ ' $\mathrm{A}$ is identical to $\mathrm{B}$ ' I mean what Leibniz would have meant, namely, that were one to speak truly of $A$, one would thereby speak truly of $B$, and conversely. The claim being pondered here is whether the pen and the book are one and the same object, a query distinct from the triviality of asking whether we may imagine a compound object consisting of the pen and the book as parts. Many philosophers, having presumed a pair of objects to be distinct, have inquired into the necessary and sufficient conditions of their individuation. No philosopher, to my knowledge, has ever enquired of objects presumed to be distinct whether they might be identical.

12 Whatever reasons, if any, she might have for believing the pen and the book to be identical are irrelevant here. Imagine simply that she has her reasons, and remember that, prior to the advent of quantum theory, no one had any reason either to believe that a nuclear particle could be in two places at once, though that is now a compelling explanation for most variants of the classical two-slit experiment. 
500 grams, but apparently not 350), but then attributes the bifurcation to a difference in measuring technique rather than substance. (In one case we are measuring the object "in a pen-like way", in the other "in a book-like way"; the former yields 5 grams, the latter 500.)

Put another way, whenever I suggest that some predicate, relational or otherwise, is testably true of either the pen or the book, she agrees with me. Whenever I go on to suggest, however, that the predicate entails the negation of some other predicate, she refuses to accept the entailment, pointing out that I am thereby obviously begging the question of the identity of the pen and the book. Since the world of objects I encounter appears to her exactly as it does to me, I am prohibited from bringing counterevidence against her identity claim without, from her perspective, begging the question. Yet she obviously construes my world differently, for her reconstrual makes a difference: if uncountered, I should soon have fewer pens in my possession. ${ }^{13}$

Clearly, I am trapped with no escape. But then, generalizing, it follows that the presumptions that we have become accustomed to making about the logic of identity must be mistaken. I and everyone else encounter the objects of the world through engendered habits of identifying and distinguishing that resist emendation. They are, in Collingwood's words, the absolute presuppositions upon which further enquiry rests. ${ }^{14}$ If I am to learn from the conversations of others, however, and to do so without prejudice, I must refrain from begging the question of whatever contrary identity claims they may presuppose. But then I must avoid altogether drawing negative inferences.

Readers familiar with the history of mathematical thought during the first half of the 20th century will by now have sensed a resonance, for I am hardly the first to have suggested that our inferences must be restricted with respect to negation if we are to think carefully. A similar claim lay at the heart of the intuitionist attack on the formalist program in metamathematics, a campaign that failed, I shall suggest, from timidity rather than arrogance, for the very notion of negation itself, rather than negative inferences alone, must be avoided. But let's move step by step.

${ }^{13}$ Note the crucial difference between my adversary asserting her identity claim, come what may, and maintaining a testable assertion in the face of contrary evidence. Were she guilty of the latter, she would have to deny some testable assertion that I accept, or presume some assertion that I deny. Here, however, we agree on every testable assertion. Her claim, therefore, unlike the evasions of a conventionalist, is as methodologically sound as my own.

${ }^{14}$ See Part I of Robin Collingwood's An Essay on Metaphysics (Oxford: Clarendon Press, 1940), pages 3-77. 


\section{Wittgenstein, Popper and Contradiction}

In 1928 Ludwig Wittgenstein attended a lecture in Vienna by the eminent topologist Luitzen Brouwer, the most distinguished proponent of intuitionism, an encounter that prompted Wittgenstein's return to philosophy and his engagement with the enquiries that resulted, a quarter-century later, in the publication of Philosophical Investigations. ${ }^{15}$ Wittgenstein had intended to include within the book a series of remarks on the foundations of mathematics. Dissatisfied, however, he chose to exclude them from the publication, ${ }^{16}$ and quite rightly so, for they encompassed suggestions of such startling absurdity that only an account of unprecedented perspicacity could have rendered them ponderable, much less palatable, to readers.

Scattered throughout the remarks, for example, were comments that seemed to imply that contradictions found within proofs were either unintelligible or innocuous, and hence the search for consistency in mathematics was misguided. ${ }^{17}$ Exactly what Wittgenstein had in mind is controversial. We may garner a fairly clear notion of what was troubling him, however, by imagining how he might have responded to, say, Popper's demonstration of comparable vintage of the presumption among logicians that from a contradiction one may infer any assertion whatsoever, "one of the few facts of elementary logic", Popper assures us, "which are not quite trivial and deserve to be known and understood by every thinking man". ${ }^{18}$ Popper's argument is as good as any and better than most, for it is characteristically clear. If, upon examination, it should prove unintelligible, then little hope of sense remains for any other.

${ }^{15}$ See Raymond Monk, Ludwig Wittgenstein: The Duty of Genius (London: Jonathan Cape, 1990), pages 249-51. Wittgenstein's Philosophical Investigations was published in Oxford by Basil Blackwell in 1953 with a translation by Elizabeth Anscombe.

${ }^{16}$ See the Editor's Preface to Ludwig Wittgenstein's Remarks on the Foundations of Mathematics (Oxford: Basil Blackwell, 1967), pages vi-vii. Hereafter Wittgenstein, RFM.

17 See, for example, Appendix I to Part I of Wittgenstein, RFM, sections 11-18; Part II, 7778; Part III, 55-60; and Part V, 8-13, 21-22, 27-30. The concluding reflection of section 17, Appendix I to Part I, is typical: "(The superstitious fear and awe of mathematicians in face of contradiction.)"

18 Karl Popper, "What is Dialectic?", Mind (New Series) 49 (1940); reprinted as chapter 15 of Conjectures and Refutations (London: Routledge \& Kegan Paul Limited, 1969 [1963]), page 317 . 
Suppose, Popper says, that we have derived a contradiction within a proof - a sentence of the form '( $p$ and $-p)$ ' implying, by definition, that both of its conjuncts are true.

$$
\text { ( } p \text { and }-p)
$$

From the first of the conjuncts we may infer ' $p$ or $q$ ', where ' $q$ ' stands in place of any assertion whatsoever.

$$
\text { ( } p \text { or } q)
$$

For, as a quick check by truth-table will attest, there is a valid rule (Rule 1) licensing the inference:

Rule 1: the material conditional ' $p$ only if ( $p$ or $q)$ ' could be false only if the antecedent is true and the consequent false; but if ' $p$ ' is true, so is ' $(p$ or $q)$ '; hence the conditional is true.

'p or $q$ ' is therefore true. From ' $(p$ or $q)$ ' and the second conjunct '- $p$ ', however, we may then deduce ' $q$ ' itself.

For there is another valid rule (Rule 2) licensing this inference as well:

Rule 2: the material conditional '( $(p$ or $q)$ and $-p)$ only if $q$ ' could be false only if the antecedent were true while ' $q$ ' were false; but if ' $q$ ' is false, then '((p or $q)$ and $-p)$ ' is false regardless of whether ' $p$ ' is true or ' $p$ ' is false (that is, '- $p$ ' is true).

' $q$ ' is therefore true as well.

From a contradiction, or so Popper concludes, we may infer any assertion whatsoever. Contradictions must therefore be avoided, for they render proofs incapable of discrimination.

What's wrong with Popper's argument? Imagine what Wittgenstein might have said in response to it. Consider the contradiction '( $p$ and $-p)$ ' with which it begins. Either the sentence is unintelligible or we must understand what it means as an assertion within the proof. If it is unintelligible, then nothing can follow from it, for we can deduce nothing from nonsense. To understand what an assertion means, however, as Donald Davidson was later to insist, is to understand its truth conditions - to understand it, that 
is, as if it were true. ${ }^{19}$ The assertion 'It is raining now', for example, is true if and only if it is raining now, but 'It is raining now' then, and only then, means it is raining now.

For Popper's proof to progress, therefore, we must comprehend '( $p$ and $-p)$ ' as if it were true. But then, when drawing inferences from it, we must only use rules that are valid both of worlds within which '( $p$ and $-p)$ ' is true and of worlds within which, if ' $p$ ' is true, then ' $-p$ ' is false (and conversely).

Popper's Rule 1 is valid of such worlds: the conditional ' $p$ only if ( $p$ or $q)$ ' is true whatever the truth-value of ' $p$ ', regardless of the truth-value of '- $p$ ', and hence true of all worlds within which '( $p$ and $-p)$ ' is true.

Popper's Rule 2, however, is invalid of such worlds, for if ' $q$ ' is false, then the conditional '( $(p$ or $q)$ and $-p)$ only if $q$ ' is false whenever ' $p$ ' and ' $-p$ ' are true.

Rule 2, therefore, cannot be used to draw valid inferences from '( $p$ and $-p)$ ', for it relies essentially on the notion of negation, and any rule that does so cannot validly be applied to ' $(p$ and $-p))^{20}$

To Wittgenstein, therefore, Popper's proof collapses into incoherence. Popper has admitted into it a sentence '( $p$ and $-p)$ ' that could be meaningful only within a world in which both ' $p$ ' and '- $p$ ' were true, and yet has used a rule of inference (Rule 2) valid only of worlds prohibiting their joint truth. He has, in effect, presumed the consistency of every possible world in demonstrating the validity of his rules of inference, while permitting those rules to be applied to a description meaningful only of an inconsistent world. Either the contradiction is meaningless, or Popper's Rule $\mathbf{2}$ (and other rules like it) must be inapplicable to it. Properly understood, therefore, contradictions are innocuous: if unintelligible, they are useless; if intelligible, they immunize themselves.

${ }^{19}$ See the papers reprinted as essays 1-5 in Donald Davidson, Inquiries into Truth and Interpretation (Oxford: Clarendon Press, 1984). Hereafter Davidson, ITI.

${ }^{20}$ Within the propositional calculus, a negative inference, roughly put, is any wellformed formula that is or encompasses the negation of a well-formed formula found within its premises, and any rule licensing such an inference relies essentially upon negation. A logic restricted to rules without negation would include modus ponens but would exclude almost all inferences classically licensed by truth-functional equivalencies (e.g. De Morgan's transformations, the inference from '( $p$ only if $q)$ ' to '(-p or $q)$ ', or from ' $p$ ' to '-(-p)' and conversely). In quantification theory, the customary conversion of the quantifiers would be prohibited. The laws of Excluded Middle and Contradiction would be retained but, deprived of nonconstructive power, would be uninteresting. 
Wittgenstein's counterthrust cuts deeply, for it implies that Popper's argument, and every other resting upon negative inferences, begs the question of consistency. Since we cannot know the consistency of any set of premises complex enough to be of mathematical interest, we must avoid rules of inference that presuppose it. We must therefore avoid rules of inference that rely essentially on negation, reaffirming exactly the conclusion that we drew earlier from our consideration of identity claims.

\section{The Unintelligibility of Negation}

Wittgenstein remained dissatisfied with his remarks on mathematics and rightly so, for he wished on the one hand to draw the poison from contradictions found within proofs, while retaining on the other hand the full force of logical incompatibility (for example, that a surface cannot logically be at once both red and green). He was too good a logician, fortunately, unlike some of his followers, to pretend that he had rendered the incoherence innocuous.

Earlier, the intuitionists had encountered a similar though inverse incoherence. Unable to conceive of a completed infinite, they tried to block proofs engendering it by redefining negation to exclude the Law of Excluded Middle, the principle that licenses the placing into proofs of assertions of the form (' $p$ or $-p$ '), for every one of the classical proofs about the completed infinite depends upon it. Unfortunately, the intuitionists wished at the same time to retain the Law of Contradiction, the principle licensing the placing into proofs of assertions of the form '- $(p$ and $-p)$ '. Although Arend Heyting showed in 1930 that one could formally redefine negation to that end, most mathematicians, including many otherwise sympathetic to the program of avoiding completed infinities, sensed incoherence. One need, after all, only understand the notions of asserting, negating and conjoining to comprehend the latter law, but they in turn suffice to define alternation (in its classical sense) and hence, it would seem, to render the former law as intelligible as the latter. ${ }^{21}$

${ }^{21}$ Arend Heyting, "Die formlen Regeln der intuitionistischen Logic", Sitzungsberichte der Preussischen Akademie der Wissenschaften, Physikalisch-mathematische Klasse (1930), pages 42-56; and in the same publication, "Die formalen Regeln der intuitionistischen Mathematik", pages 57-71 and 158-69. Unsurprisingly, Kurt Gödel's demonstration in 1932 that Heyting's calculus could be reinterpreted "in terms of the concepts of the usual sentential logic and of the concept ' $p$ is provable'" was read by most mathematicians as having given sense to a system previously unintelligible. See Gödel's "Zum intuitionistischen Aussagenkalkül", Akademie der Wissenschaften in Wien, Mathematisch-naturwissenschaftliche Klasse, Anzeiger 69 (1932); reprinted in Ergebnisse eines mathematischen Kolloquiums 4 (Vienna: Verlag Franz Deuticke, 1933), pages 39-40; reprinted under the title "An Interpretation of the Intuitionistic Sentential Logic", translated by J. Hintikka and L. Rossi, in The Philosophy of Mathematics, edited by Jaakko 
Wittgenstein and the intuitionists courted incoherence, for they wished to exclude negation from inferences while retaining it within assertions. But negation is unintelligible within assertions as well, and the proof is transparent.

As Alfred Tarski insisted in 1933, the notion of truth is intelligible for a language only if we can derive from it the necessary and sufficient conditions for the truth of every assertion within the language. ${ }^{22}$ To express the truth conditions of any assertion within a language, however, we need know only how to mention and to use it, for we need only mention the assertion on the left side of a biconditional, and use it (or a translation of it) on the right side, to express its truth conditions. 'It is raining now', for example, is true if and only if it is raining now. To understand its truth conditions is therefore to understand what it means, for 'It is raining now' means that it is raining now. The conditions of truth and intelligibility thus coincide for assertions, as noted above.

Unfortunately, we can give neither necessary nor sufficient conditions for the negation of an assertion, and hence the notion of negation is unintelligible. The negation of an assertion would, if intelligible, be true by definition if and only if the assertion itself were false. The intelligibility of negation hinges therefore on the intelligibility of falsity. There is a radical asymmetry, however, between the intelligibility of the notion of truth and that of falsity, for whereas conditions can be expressed for the truth of any assertion, none can be given for its falsity: the corresponding biconditional (e.g. 'It is raining now' is false if and only if ... ') is incomplete. Since we are unable to express necessary and sufficient conditions for an assertion to be false, the notion of falsity is unintelligible. But then negation is unintelligible as well. If we are to think precisely, therefore, we must avoid the notions of falsity and negation altogether.

Hintikka (Oxford: Oxford University Press, 1969), pages 128-29. Heyting's Intuitionism: An Introduction (Amsterdam: North-Holland, 1956) remains to this day the best introduction to the subject in English.

22 Alfred Tarski, "Der Wahrheitsbegriff in den formalisierten Sprachen", translated from the Polish by L. Blaustein, Studia philosophica 1 (1936; submitted 1933), pages 261-405, reprinted in translation by J. H. Woodger as "The Concept of Truth in Formalized Languages", in Tarski's Logic, Semantics, Metamathematics: Papers from 1923 to 1938 (Oxford: Clarendon Press, 1956), pages 152-278. 
No wonder negation has proven so useless in the everyday world, as so many philosophers in our century have remarked in amazement. ${ }^{23}$ When the engine of language is put to work rather than idling, in Wittgenstein's metaphor, negation disappears in the dust.

\section{Overhearing Truths}

Logic, if unpresumptuous, must be constructive: negation must be avoided in both inference and assertion, for the notion of falsity upon which it rests is unintelligible. The uses of logic without negation, however, are transparent, for with consistency assured, criticism coincides with the hard task of constructing alternatives. With trivial tools, however, one may build structures of unlimited complexity, ${ }^{24}$ as the avoidance of negation assuredly confirms, for it voids as well the distinction between truth and falsity and therewith the penultimate dogma of empiricism, as Donald Davidson, after Quine, almost insisted.

In 1936 a young Willard Quine, bringing the weapons of relativity theory to bear upon language, fired a shot across the bow of empiricism to be heard around the world, the first salvo of an attack that by 1960 had obliterated the distinction between meaning and reference, and hence the pretension that a sentence could be known to be true in virtue of its meaning alone: without knowing what a speaker means, reference is inscrutable; without knowing to what a speaker refers, meaning, and thus translation, is indeterminate. ${ }^{25}$

${ }^{23}$ See, for example, Bertrand Russell's affirmation of 1948 that "the world can be described without the use of the word 'not'" (Human Knowledge, its Scope and Limits (New York: Simon and Schuster, 1948), page 520); or Peter Geach's acknowledgment in 1956 of "the virtual absence of propositional negation from 'ordinary language'" (from an article on the Law of Excluded Middle in Supplementary Volume 30 of the Proceedings of the Aristotelean Society, 1956, reprinted in Logic Matters (Berkeley: University of California Press, 1980), page 75.).

24 This has often been overlooked by critics. As Donald Davidson once remarked in exasperation with respect to the theory of truth, "Critics have often made the error of thinking that since the theorems that show a theory to be correct are trivial, the theory or the concept of truth it characterizes, must also be trivial." (Introduction to Davidson, ITI, page xv)

25 The crucial works by Quine are "Truth by Convention", in Philosophical Essays for A. N. Whitehead, edited by O. H. Lee (New York: Longmans, 1936), pages 90-124, reprinted in Quine's The Ways of Paradox, revised and enlarged edition (Cambridge: Harvard University Press, 1976), pages 77-106; "On What There Is", Review of Metaphysics 2 (1948), pages 21-38, and "Two Dogmas of Empiricism", Philosophical Review 60 (1951), pages 20-43, reprinted in From a Logical Point of View (Cambridge: Harvard University Press, 1953), pages 1-19 and 20-46 respectively; 
The distinction that Quine assailed had appeared in philosophy in many guises and under many aliases, among them the analytic/synthetic, necessary/contingent, apriori/aposteriori and conventional/empirical. Quine exploded them all, hardly however, as the wistful misreadings of Wittgensteinians would suggest, by arguing that the notions were useless, but rather by insisting that they must be reconstrued to be of only comparative use, giving contrary directions to the same continuum. The assertion 'White horses are white', for example, is more analytic than (or, if read in the other direction, less synthetic than) the assertion 'White horses breathe', but neither is analytic (or synthetic), for there is 'no fact of the matter' to which a linguist learning the language could appeal to distinguish meaning from reference. Such a linguist, overhearing an assertion that seems patently false, must therefore choose either to affirm the diagnosis, or to act charitably, presuming the assertion true but beyond his or her competence to understand. Quine, on pragmatic grounds, recommended the latter: "... assertions startlingly false on the face of it are likely to turn on hidden differences of language". ${ }^{26}$

Quine's insistence upon the primacy of comparative predicates, pragmatic to the core, was nearly exhaustive. Monadic predicates, he concluded, were unessential to science and hence to a right registering of the world: we need comparative predicates like 'is faster than', 'is bigger than' or 'is heavier than' that relate events to one another measurably, but can do without 'is fast', 'is big' or 'is heavy'. ${ }^{27}$ Only one monadic predicate escaped relativization: the predicate 'is true' remained for Quine inviolate. It never occurred to Quine, therefore, that his arguments could be brought to bear against the distinction between truth and falsity itself.

By the 1970s, however, it had dawned upon Donald Davidson that Quine's example of a linguist preoccupied by radical translation could be generalized. ${ }^{28}$ Quine, suspicious of all talk of the mental, had focused upon meaning and reference as aspects of the act of asserting independent of the intentions and beliefs of the speaker and hearer, and

Word and Object (Cambridge: M.I.T. Press, 1960), hereafter Quine, WO; and the collection Ontological Relativity and Other Essays (New York: Columbia University Press, 1969).

${ }^{26}$ Quine, WO, page 59. Quine's maxim is customarily referred to as 'the Principle of Charity', a phrase introduced by Neil Wilson in his article "Substances Without Substrata", Review of Metaphysics 12 (1959), pages 521-39 but rendered commonplace through the commentaries of Donald Davidson.

27 The conclusion is a natural consequence of Quine's program. Surprisingly, however, the only occasion known to me on which he explicitly said so was in response to a question put to him in my presence following an address at York University in February 1991.

${ }^{28}$ See in particular essays 9-12 in the section entitled "Radical Interpretation" in Davidson, ITI, pages 123-79. 
hence had presumed a sharp distinction between the objective and the subjective aspects of assertion. To overhear an utterance that we find comprehensible enough to construe as an assertion, however, even when made by a speaker in our own language, is to encounter an expression of a belief held to be true; and since the speaker has found it useful to express that belief within our world, its expression, even when calculated to mislead us, must be evidence prima facie of its truth.

Any encounter with someone making an assertion requires us to interpret what is being asserted by attempting to comprehend what beliefs about the world are being expressed. But then, contra Quine, we must act charitably: we must attempt almost always to interpret the assertions we overhear as expressing true beliefs, for we must share with the speaker a massive background of beliefs about the world, almost all of which are true, to be able to identify by contrast the occasional misdirection or misstatement. Although any of our beliefs may be false, the bulk of them must be true. Scepticism, therefore, is statistically impossible.

But if we must assume that almost everything we believe is true, and that almost all of our beliefs are shared by every speaker we overhear, then it follows that the world itself must be pretty much the way we and everyone else believe it to be.

... the general outlines of our view of the world are correct; we individually and communally may go plenty wrong, but only on condition that in most large respects we are right. It follows that when we study what our language - any language - requires in the way of overall ontology, we are not just making a tour of our own picture of things: what we take there to be is pretty much what there is. ${ }^{29}$

The distinction between conceptual scheme and content, a dogma of empiricism presumed unwittingly by Quine, is untenable. But then, contra Quine, ontological relativity is incoherent as well. ${ }^{30}$

Davidson's reconstrual of Quine has profound implications for our understanding of how we learn, and hence how we should teach others. We are often, and even intentionally, misled by assertions we overhear. If Davidson is right, however, we are almost always misled by the expression of truths whose irrelevance we misconstrue, rather than

${ }^{29}$ Davidson, Introduction to ITI, page xviii \& xix. The key essay is "On the Very Idea of a Conceptual Scheme", Proceedings and Addresses of the American Philosophical Association 47 (1974), reprinted as chapter 13 in Davidson, ITI, pages 183-98.

30 "Our general method of interpretation forestalls the possibility of discovering that others have radically different intellectual equipment. ... Without such a dualism, we cannot make sense of conceptual relativism." Davidson, Introduction to ITI, page xviii. 
falsities. Human disputation feeds upon fanaticism rather than falsity, a focusing upon too few and disparate truths at the expense of others. If irrationality arises from misjudgements about the relative significance of truths rather than misallegiances to falsities, then many venerable presumptions about education require revision: the aim of instruction must be to stimulate acknowledgment and respect for unrecognized truths rather than to eradicate falsities. Critical thinking is idolatry.

Davidson, however, never drew the deepest consequence of his argument, for he, like Quine, remained enraptured with the notion of truth. We are sometimes, indeed, and even intentionally, misled by being told that $A$ is $B$, only to discover later, perhaps to our dismay, that $\mathrm{A}$ is $\mathrm{C}$; and we may often have good reason to complain. Our complaint, however (and here I step decisively beyond Davidson), can only be that we were led to misconstrue the significance of the assertion we overheard. If we have been misled, it is because we have inferred, upon hearing that $A$ is $B$, that $A$ is not $C$. As noted earlier, however, we should have avoided the inference: negative inferences beg the question of identity, and nowhere more transparently than here, for the $A$ that is $C$ would be $B$ as well to anyone having identified it with anything that is $\mathrm{B}^{31}$

Davidson, therefore, outdistanced Quine only by rendering untenable the very distinction between truth and falsity, the penultimate dogma of empiricism to which both he and Quine remained attached. For if, with Davidson, we are obliged to act as if almost every belief whose expression we overhear is true, then our task can only be to accommodate every belief we hear expressed within the encompassing body of beliefs we bring to our encounter, positioning them with respect to their relative significance and power. That task would remain the same were we to construe every belief whose expression we overhear as true but, in some cases, of vanishingly small significance. But then the distinction between truth and falsity has been rendered irrelevant: having ascertained rightly the relative insignificance of a belief, the question of its truth or falsity evanesces.

Davidson's argument, pushed to its conclusion, renders the notion of truth indiscriminate. Our cognitive quests, rather than being 'searches for truth', would more aptly be construed as finding a place for novel expressions of belief within the patterns of relative significance, value and use we bring to their assessment, a task of coherent reconstruction akin to fitting a piece into a puzzle - exactly as Nelson Goodman has suggested.

${ }^{31}$ With reference inscrutable and translation indeterminate, as both Quine and Davidson insist, negative inferences beg all sorts of other questions as well. 


\section{Goodman's Worlds}

In 1985 Nelson Goodman came as close to hitting the logical nail on the head as any philosopher ever has. Truths, Goodman recognized, are almost always irrelevant to the discriminations we must make among assertions, hence the 'search for truth' must be reconstrued within a broader context of enquiry. Our task, even in science, is to arrange assertions in right relationships with one another - a matter of rightness of fit, or useful coherence.

... a statement is true, and a description or representation right, for a world it fits. ... Rather than attempting to subsume descriptive and representational rightness under truth, we shall do better, I think, to subsume truth along with these under the general notion of rightness of fit. ... The differences between fitting a version to a world, a world to a version, and a version together or to other versions fade when the role of versions in making the worlds they fit is recognized. And knowing or understanding is seen as ranging beyond the acquiring of true beliefs to the discovering and devising of fit of all sorts. ${ }^{32}$

Learning how to think rightly and thus inquisitively is learning how to construct rather than criticize; and since we can only construct something from elements already at hand and hence already arranged into a world, it is to learn how to reconstruct a better world from a world we encounter rather than seeking the truth about it. ${ }^{33}$ The arts, therefore, are the models for science and philosophy, rather than the reverse, for they encompass the reconstructions of the world we most freely undertake.

So far, so good. What then kept Goodman from driving the nail home without destroying the uniqueness and identity of our world? Goodman has long believed, and correctly, that every word has a unique meaning as does every assertion, and hence, with Quine, that quests for meaning and synonymy are useless. ${ }^{34}$ If then there should be incompatible yet equally coherent and encompassing networks of assertions describing our world - incompatible right world-descriptions - each would be unique and irreducible to any other.

32 Goodman, WWM, pages 132 and 138.

33 "The many stuffs ... that worlds are made of are made along with the worlds. But made from what? Not from nothing, but from other worlds. Worldmaking as we know it always starts from worlds already on hand; the making is a remaking." Ibid., page 6.

34 The central essays are "On Likeness of Meaning", Analysis 10 (1949), pages 1-7, and "On Some Differences about Meaning", Analysis 13 (1953), pages 90-96, reprinted in Goodman's Problems and Projects (Indianapolis: Bobbs-Merrill Company, 1972), pages 221-30 and 231-38 respectively. 
Goodman, unfortunately, assumed without question that negation is intelligible, and hence, like Wittgenstein, that a predicate, rightly applied to an object or event from within a world-description, excludes others. Convinced, however, that the same subject term could occur within distinct world-descriptions, and that incompatible predicates within alternative world-descriptions could be rightly appended to the same subject term (e.g. the assertions 'The earth moves clockwise' and 'The earth moves counterclockwise' may be affirmed with equal right, but only within alternative worlddescriptions), ${ }^{35}$ Goodman concluded that we are encompassed about by incompatible right world-descriptions. Since whatever world is described by a right world-description can only be accessed by describing it from within that world-description, it follows, Goodman concluded, that there must be as many actual worlds as there are right worlddescriptions. ${ }^{36}$ Misunderstanding the logic of identity, in other words, Goodman concluded that the worlds described within right world-descriptions, being distinguishable from one another, were therefore prohibited from being identical.

Ever consistent, Goodman made a comparable slip with respect to the identity of works of art. One may readily distinguish my dog, for example, from any painting, photograph or film that represents her, for one can apply distinct predicates to them. Goodman concluded without warrant, however, that I should be mistaken, upon looking at a painting, photograph or film of my dog, to identify what I see by doing so with my dog. A painting, photograph or film representing my dog, he concluded, must therefore be a symbol - an event that refers to my dog within some conventional symbol system that I have learned to decipher rather than an object that (re)presents her to me.

... to represent is surely to refer, to stand for, to symbolize. Every representational work is a symbol; and art without symbols is restricted to art without subject. $^{37}$

Having slipped twice, Goodman made the best of it. If representation must be denotation, and we must have worlds without $a$ world, then the only unity available to us must come from above rather than beneath - from an encompassing 'theory of symbols'.

35 See section 1, "Worlds in Conflict", of chapter 7, "Of Rightness of Rendering", of Goodman, WWM, pages 109-16. The example given is from note 4 on page 111.

36 Ibid., sections 1-3 of chapter 1 , pages 1-7.

37 Ibid., page 58. When it was pointed out to Goodman that he had simply assumed, without argument, that "the core of representation is denotation", he could only agree, suggesting lamely, after pondering the matter, that by proposing a categorial system that "has no truth-value", he was simply showing "what it could do ... what is called for in such cases is less like arguing than selling". Ibid., page 129. 
So long as contrasting right versions not all reducible to one are countenanced, unity is to be sought not in an ambivalent or neutral something beneath these versions but in an overall organization embracing them. ... My approach ... is through an analytic study of types and functions of symbols and symbol systems. ${ }^{38}$

Unfortunately, to construct a theory of symbols encompassing incompatible right worlddescriptions, one must be able to describe from without both the world-descriptions and the worlds they describe, for otherwise the semantic relations between description and described would remain unspecifiable. As Goodman has insisted, however, one can comprehend a world only from within its world-description. To search for an encompassing theory of symbols, negation presumed, is therefore fruitless.

Goodman was compelled to deny the identity of our world, and to construe artistic representation as symbolic, by a misunderstanding of the logic of identity. Had he recognized that we must avoid negation if we are to think with precision, and hence that distinction and identity are relative, he assuredly would have recognized that we may both distinguish and identify events across the worlds that we construct and hence both distinguish and identify the worlds themselves. He would also have recognized that works of art may (re)present to us objects, events and worlds that are both distinguishable from and yet identifiable with the objects, events and world within which we live, move and have our being - as Lumière recognized a century ago. ${ }^{39}$ Only

${ }^{38}$ Ibid., page 5. The subtitle of Goodman's Languages of Art is 'An Approach to a Theory of Symbols'.

39 On two occasions, Goodman came very close to asserting the relativity of identity but never drew the appropriate conclusion. Early on in WWM he remarks that, "If there is but one world, it embraces a multiplicity of contrasting aspects; if there are many worlds, the collection of them all is one. The one world may be taken as many, or the many worlds taken as one; whether one or many depends on the way of taking. ... all we learn about the world is contained in right versions of it; and while the underlying world, bereft of these, need not be denied to those who love it, it is perhaps on the whole a world well lost". (Ibid., pages 2 and 4) And when discussing later Eddington's renowned example of the relation between the table I see before me and the structured molecules of which it consists, Goodman remarks: "Is the seen table the same as the mess of molecules? To such questions, discussed at length in the philosophical literature, I suspect that the answer is a firm yes and no. The realist will resist the conclusion that there is no world; the idealist will resist the conclusion that all conflicting versions describe different worlds. As for me, I find these views equally delightful and equally deplorable - for after all, the difference between them is purely conventional!" (Ibid., page 119.) Unfortunately, as Goodman realizes in his more exact moments, his commitment to negation, and therewith conflicting truths, entails worlds that are logically incompatible and hence incapable of being identified. (Ibid., page 110). So near and yet so far! 
under these conditions could a search for an encompassing theory of symbols be successful. But then, of course, the root reason for the search would have disappeared.

We must remember, however, that Goodman was right in his most important claim: to construct is to reconstruct, whether in art, philosophy or science, and hence the arts must serve as models for reconstructing the world. How then must we train ourselves to learn to reconstruct worlds artistically? If, as Goodman insists, construction is reconstruction wherever it occurs, then learning to construct must be learning to reconstruct. But that, as Robin Collingwood insisted, is to learn to think historically.

\section{The Last Dogma of Empiricism}

Quine and Davidson attacked many of the dogmatic distinctions of empiricism, and did so effectively. They remained committed, however (as Goodman has been, in practice) to a last dogma of empiricism whose tenability they had unwittingly destroyed, namely the distinction between the study of an art, philosophy or science and the study of its history.

In 1962 Thomas Kuhn pried open the minds of a number of philosophers to the importance of history by insisting that major changes occur in a science only when a novel paradigm emerges, attracting those young enough (or mentally spry enough) to learn it as their working language, thus enabling them to recast the world taxonomically in a fresh and fruitful way, while repelling those too old to understand it, neither group being capable of comprehending the language of the other. As the younger workers replace the older, the newer paradigm becomes dominant, having bypassed rather than refuted its predecessor. ${ }^{40}$

Kuhn, having had the temerity to suggest that science advances in its most revolutionary periods without attending to the truth or falsity of its claims, was attacked savagely by both positivists and Popperians for subverting its objectivity and hence rationality. ${ }^{41}$

40 Thomas Kuhn, The Structure of Scientific Revolutions (Chicago: University of Chicago Press, 1962). Kuhn consistently reaffirmed the linguistic metaphor: "Proponents of different theories are, I have claimed, native speakers of different languages." See his "Objectivity, Value Judgment, and Theory Choice", in The Essential Tension (Chicago: University of Chicago Press, 1977), page 320.

${ }^{41}$ J.N. Watkins, toeing the party line, accused Kuhn of reducing science and its revolutions to a "closed society, intermittently shaken by collective nervous breakdowns", a charge trumped by Imre Lakatos with his suggestion that Kuhn "vindicates, no doubt unintentionally, the basic political credo of contemporary religious maniacs ..."; " ... scientific revolution is irrational, a matter of mob psychology". See their respective essays "Against 
Kuhn replied, with scholarly glee, that only someone blind to the history of science could pretend that the hypothetico-deductive model had ever applied to any significant part of it; and since science, rather than philosophy, is the paradigm of rationality we wish to understand, the reconstructive rather than critical method upon which scientists rely, akin to the reconstructive methods of historians and artists, is the rational paradigm upon which philosophy, too, should model itself.

Had Kuhn himself been sufficiently acquainted with the history of philosophy, he would have recognized that he was re-enacting, albeit in different costume, the role that had immunized and isolated Collingwood from the plague of positivism a quarter-century before. Collingwood, writing between the world wars, had insisted that metaphysical enquiry, the core of philosophy, was a historical endeavour. The only coherent role for a metaphysician was to register the absolute presuppositions prevalent in some historical period, for apart from their historical context the presuppositions lacked sense. To learn to think constructively as a philosopher, Collingwood concluded, one must immerse oneself in the history of philosophy, exactly as a student of music, for example, has to learn to write like Bach, and then like Beethoven and then like Wagner, etc., to be able to command the tools of musical composition available in our era. To become competent with the tools available for reconstructing the philosophy of politics, for example, one must learn to identify oneself imaginatively with Plato, and then Hobbes and then Kant, etc., thinking as they thought about the 'state' to understand what each had meant by the word, for how they had thought by means of it was unique to their historical epochs, and thus irreducible. ${ }^{42}$

Collingwood was dismissed without hearing by most philosophers as a dilettante perversely disrespectful of the objectivity of philosophy. ${ }^{43}$ Simply put, however, he was despised for rejecting the distinction between the contexts of discovery and justification, the last dogma of empiricism, as Kuhn was to reject it, and be rejected,

Normal Science" and "Falsification and the Methodology of Scientific Research Programmes" in Criticism and the Growth of Knowledge (Cambridge: Cambridge University Press, 1974 [1970]), pages $25-37$ and 91-196, the latter a revision of an essay previously published in 1968 . The quotations are from page 26, and pages 93 and 178.

42 See the reference in note 11 above but also Collingwood's An Autobiography (Oxford: Clarendon Press, 1939) and The Idea of History (Oxford: Clarendon Press, 1946), especially the Introduction and Part V ("Epilegomena"). Hereafter Collingwood, IH.

${ }^{43}$ Even the executor of Collingwood's literary estate, James Knox, resisted publishing many of his later writings on history and philosophy, thinking them, in company with many of his published books, so absurd as to be incapable of being rendered consistent "even with themselves", "marred by febrility and overweening confidence", explicable only as the result of a mind corrupted by encroaching illness. See Knox's Preface to Collingwood, $I H$, pages xviii, xix and $x$ xi. 
after him. If, however, as Davidson has implied, we as philosophers must presume that every assertion we overhear is true, and, after Goodman, that the philosophical games we play must be as reconstructive as every other art, and hence that we must learn to learn, even when pursuing the arts of science or philosophy, as artists have always learned to learn, then it follows that Collingwood and Kuhn were correct. The assertions that we overhear as philosophers and that, after Davidson, we must interpret as true, must encompass those made by the philosophers of the past. If we are to learn how to re-philosophize in our own era, we must learn to think as they thought, in their terms, exactly as other artists must learn from the history of their art how to reconstruct its worlds in our own.

\section{Conclusion}

The glory of philosophy in the 20th century has been, for me, the pragmatic reformation of the dogmas of empiricism, historically construed, and therewith the reaffirmation of Kant's program of reconstructive synthesis. Few philosophers, however, have dared to imagine how profoundly revisionary and hence wondrously absurd that reformation would become, for it reaches to the roots of logic itself, and few aspects of the world reaffirm the need for that reconstruction more profoundly than the mysterious identities that Louis Lumière assimilated in 1895 when establishing the art of filmmaking, and that, a century later, have focused the conclusions summarized here. 